Revista Educação e Políticas em Debate - v. 7, n. 2, p. 244-262, mai./ago. 2018 - ISSN 2238-8346

\title{
O protagonismo da CNTE nas disputas pelas garantias constitucionais no campo da educação
}

\author{
Prominence of the CNTE in the disputes over constitutional guarantees in the field \\ of education \\ Proéminence de la CNTE dans les disputes pour les droits constitutionnels au champ \\ de l'éducation
}

Elisângela Alves da Silva Scaff ${ }^{1}$

Universidade Federal do Paraná

Andréa Barbosa Gouveia ${ }^{2}$

Universidade Federal do Paraná

Marcos Alexandre dos Santos Ferraz ${ }^{3}$

Universidade Federal do Paraná

Resumo: Este artigo tem como objetivo analisar o papel dos movimentos sociais do campo educacional nos processos de elaboração e de materialização dos direitos conquistados na Constituição Federal de 1988. Para tanto, elege-se como objeto de estudo as Resoluções de Congresso da Confederação Nacional dos Trabalhadores em Educação (CNTE), no período de 1990 a 2017 , analisadas a partir de estudo documental. Tais análises permitiram identificar a trajetória de defesa da educação pública e da proteção corporativa da categoria, articuladas a questões estruturais da organização do Estado brasileiro.

Palavras-chave: Constituição Federal. CNTE. Sindicalismo Docente. Política Educacional.

Abstract: This article aims to analyze the role of social movements in the educational field in the processes of elaboration and materialization of the rights conquered in the Federal Constitution of 1988. For this purpose, the Congress Resolutions of the National Confederation of Workers in Education (CNTE), from 1990 to 2017, analyzed from a documentary study. These analyzes allowed us to identify the defense trajectory of public education and the category's corporate protection, articulated to structural issues of the Brazilian State organization.

Key-words: Federal Constitution. CNTE. Teachers Unionism. Educational Policy.

Resumé: Cet article propose une analyse sur les rôles des mouvement sociaux au champ de l'éducation dans les processus d'élaboration et matérialisation des droits ayant conquis dans la Constitution Fédérale de 1988. La recherche a élu comme objet,pour réaliser une analyse

\footnotetext{
${ }^{1}$ Doutora. Universidade Federal do Paraná UFPR). Universidade Federal da Grande Dourados (UFGD). Email: elis-scaff@hotmail.com

2 Andréa Barbosa Gouveia (Doutora). Núcleo de Políticas Educacionais (NUPE)/Universidade Federal do Paraná (UFPR).E-mail: andrea-gouveia@uol.com.br

${ }^{3}$ Marcos Alexandre dos Santos Ferraz (Doutor). Núcleo de Políticas Educacionais (NUPE)/Universidade Federal do Paraná (UFPR).E-mail: ferrazmarcos@uol.com.br
} 
documentaire,les Résolutions des Congrès de la Confédération Nationale des Enseignants (CNTE), dans la période de 1990 à 2017. Les analyses ont permis d'identifier la trajectoire de la défense de l'éducation publique et de la protection corporative des enseignants, lié aux questions structurales de l’État Brésilien.

Mots-clés: Constitution Fédérale. CNTE. Syndicalisme Enseignants. Politiques d'éducation.

\section{Introdução}

A promulgação da Constituição Federal de 1988 demarca um novo tempo na história da política brasileira. Após 21 anos de ditadura civil-militar, a construção coletiva de um novo projeto de sociedade se deu com a contribuição dos mais diversos movimentos sociais.

Paradoxalmente, tal Carta Magna atinge a maturidade ferida de morte pelo golpe de estado empreendido pelos poderes legislativo e judiciário brasileiros, com forte apoio da grande mídia nacional, em 2016, que culminou com o impedimento da Presidente eleita Dilma Vana Roussef (PT), sem a devida comprovação de crime de responsabilidade, e assunção do seu vice, Michel Temer (PMDB) à Presidência da República, processo esse marcado por "leituras elásticas" da Constituição Federal de 1988 (JINKINGS, 2016).

Consolidado o golpe em 2016, o governo de Michel Temer deu início a uma série de contrarreformas que avançam contra os principais direitos garantidos pela Constituição Federal de 1988, especialmente no que se refere às políticas sociais e à participação social nos processos de elaboração, acompanhamento e avaliação das políticas públicas.

A educação, enquanto segmento das políticas sociais, vem sendo atingida sistematicamente pela contrarreforma em curso, cujas mudanças legais estão sendo realizadas sem qualquer interlocução com os representantes dos movimentos sociais da área, assumindo caráter conservador, privatista e elitista.

Considerando tal conjuntura nos parece de fundamental importância analisar o papel dos movimentos sociais do campo educacional nos processos de elaboração e de materialização dos direitos conquistados na Constituição Federal de 1988, uma vez que estes tiveram, inicialmente, “[...] papel decisivo no processo constituinte e na elaboração dos artigos relativos à Educação [...]” (GOHN, 2009, p. 27); e, posteriormente à Constituição, foram decisivos, ao 
longo dos anos de 1990, na construção de arenas públicas, onde diversos conflitos e interesses ganharam visibilidade política (PAOLI; TELLES, 2000).

Entre os movimentos sociais que atuaram e atuam de forma incisiva em defesa da educação pública brasileira, desde os anos de 1980, podemos destacar diferentes entidades, tanto do campo de estudos e pesquisas, como a Associação Nacional de Pós-Graduação em Educação (ANPED) e a Associação Nacional de Profissionais da Administração Escolar (ANPAE) $)^{4}$, quanto no campo sindical, como a Confederação dos Professores do Brasil (CPB), atual Confederação Nacional dos Trabalhadores em Educação (CNTE), esta última tomada como objeto de estudo neste texto devido a sua articulação com projeto de pesquisa em desenvolvimento pelos autores ${ }^{5}$.

Objetiva-se analisar a trajetória de atuação da CPB/CNTE desde o processo de elaboração da Constituição Federal de 1988 até o período pós-golpe de 2016, com vistas a identificar as principais pautas defendidas na direção da consolidação dos direitos conquistados na Constituição Federal de 1988. Para o alcance desses objetivos realizamos levantamento, categorização e análise das Resoluções dos Congressos da CNTE, desde 1990 até 2017, como evidencia o quadro 1.

\footnotetext{
${ }^{4}$ Atualmente denominadas Associação Nacional de Pós-Graduação e Pesquisa em Educação (ANPED) e Associação Nacional de Política e Administração da Educação (ANPAE).

${ }^{5}$ Projeto de Pesquisa intitulado "CNTE, FENPROF e as disputas da política educacional: a luta de professores brasileiros e portugueses no período democrático recente”, financiado pelo Edital Universal do CNPq.
} 
Quadro 1: Resoluções de Congresso CNTE 1990 - 2017

\begin{tabular}{|c|l|l||}
\hline Ano & \multicolumn{1}{|c|}{ Local } & \multicolumn{1}{|c|}{ Título } \\
\hline 1990 & Aracaju - SE & Congresso Nacional de Unificação dos Trabalhadores em Educação \\
\hline 1991 & Olinda, PE & XXIII Congresso Nacional dos Trabalhadores em Educação \\
\hline 1993 & Rio de Janeiro, RJ & $\begin{array}{l}\text { XXIV Congresso Nacional dos Trabalhadores em Educação - } \\
\text { Gestão democrática: participação popular }\end{array}$ \\
\hline 1995 & Porto Alegre - RS & $\begin{array}{l}\text { XXV Congresso Nacional dos Trabalhadores em Educação: } \\
\text { educação no centro das atenções: em defesa da escola pública }\end{array}$ \\
\hline 1997 & Cuiabá, MT & $\begin{array}{l}\text { XXVI Congresso Nacional dos Trabalhadores em Educação: } \\
\text { Construindo um Plano Nacional de Educação Democrático e } \\
\text { Emancipador }\end{array}$ \\
\hline 2002 & Blumenau, SC & $\begin{array}{l}\text { XXVII Congresso Nacional dos Trabalhadores em Educação. Terra, } \\
\text { Trabalho, Salário e Educação: desafios para o século XXI }\end{array}$ \\
\hline 2005 & Brasilia, DF & $\begin{array}{l}\text { XXIII Congresso Nacional dos Trabalhadores em Educação. } \\
\text { Educação publica só é prioridade com mais financiamento: já passou } \\
\text { da hora }\end{array}$ \\
\hline 2008 & Brasilia, DF. & $\begin{array}{l}\text { XXX Congresso Nacional da CNTE. Educação pública: A diferença } \\
\text { que promove a igualdade }\end{array}$ \\
\hline 2011 & Brasília, DF & $\begin{array}{l}\text { XXXI Congresso Nacional da CNTE: a visão dos(as) } \\
\text { trabalhadores(as) em educação }\end{array}$ \\
\hline 2014 & Brasilia, DF & $\begin{array}{l}\text { XXXII Congresso Nacional da CNTE: educação, desenvolvimento e } \\
\text { inclusão social }\end{array}$ \\
\hline 2017 & Brasília, DF & $\begin{array}{l}\text { XXXIII Congresso Nacional da CNTE: Paulo Freire: educação } \\
\text { pública, democracia e resistência }\end{array}$ \\
\hline \hline
\end{tabular}

Fonte: CNTE (1990-2017).

Pretende-se, assim, reconstruir o percurso de temáticas que a CNTE elegeu como centrais para a disputa em torno da Constituição Federal, considerando a abrangência das questões educacionais constantes no capítulo referente à educação na Carta Magna, destacando-se que esta é a primeira que incorpora a valorização do magistério como princípio constitucional. Considera-se ainda o argumento de que a política pública brasileira é fortemente constitucionalizada, portanto os governos, para desenvolver políticas, disputam alterações legais, em forma especialmente de emendas. Observar em 27 anos de luta da CNTE no enfrentamento dos embates em torno da constituição é um fio condutor para análise do trabalho aqui apresentado.

\section{Da CPB à CNTE: a organização dos professores no processo de redemocratização}

Uma das importantes conquistas advindas da promulgação da Constituição Federal de 1988 foi o direito do servidor público à livre associação sindical, garantido pelo seu artigo 37, fato que provocou a transformação de antigas associações de professores e de outros 
trabalhadores em educação em sindicatos com características corporativo-trabalhistas, derivadas de uma organização sobre nova base jurídica, que lhe conferia o estatuto de representação para questões laborais (GOUVEIA \& FERRAZ, 2013, p. 117).

Desse movimento resultou a criação da Confederação Nacional dos Trabalhadores da Educação (CNTE), em 1989, filiada à Central Única dos Trabalhadores (CUT), a partir da união da Confederação dos Professores do Brasil (CPB) com a Federação Nacional dos Supervisores de Ensino (Fenase), a Federação Nacional de Orientadores Educacionais (Fenoe) e a Coordenação Nacional de Servidores do Ensino Público.

Se, por um lado, a passagem da Confederação dos Professores Primários do Brasil (CPPB) para Confederação dos Professores do Brasil (CPB), em 1979, havia rompido, no plano representativo, com a dicotomia entre professores primários e secundários, a criação da CNTE, unificando estas antigas Confederações, Federações e Coordenações por especialização ou área de atuação, conferiu uma nova característica classista - e não apenas profissional - ao movimento de trabalhadores na educação (FERRAZ, 2012; GINDIN, 2015).

A CPB foi uma das organizações protagonistas no processo de elaboração da Constituição Federal de 1988, cuja defesa das pautas de caráter democrático-popular no campo da educação se fortaleceram mediante sua atuação junto ao "Fórum Nacional em Defesa da Escola Pública" (FNDEP), criado no ano de 1986, sob a denominação inicial de "Fórum Nacional pela Constituinte”. Composto, a princípio, por 15 entidades, o FNDEP teve como objetivo aglutinar forças em defesa da educação pública e teve um papel político fundamental no processo Constituinte (BOLLMAN \& AGUIAR, 2016, p. 412).

Decorrem desse movimento garantias substanciais conquistadas no texto da Lei, como o já mencionado direito à livre associação pelos funcionários públicos, bem como a inserção, entre os princípios do ensino, da gratuidade do ensino público, da valorização dos profissionais da educação escolar, do piso salarial profissional nacional para os profissionais da educação escolar pública e da gestão democrática do ensino público.

Evidentemente não se pode negar o caráter paradoxal de tais conquistas, que circunscrevem as grandes bandeiras de luta dos movimentos dos educadores exclusivamente ao âmbito da educação pública, de forma que as instituições privadas, cuja coexistência com as instituições públicas também é garantida como princípio constitucional, no inciso III do Artigo 206, ficam dispensadas de cumprir com os demais princípios, como a gestão democrática, por exemplo. Um problema de pesquisa interessante, que não será tratado neste texto, seria investigar esta omissão do texto constitucional, não apenas sob a lógica dos interesses do 
empresariado da educação, mas também da divisão institucional - derivada da CLT e da proibição da organização sindical de professores públicos até a Constituição de 1988 - da representação dos interesses corporativo-trabalhistas dos profissionais da educação do setor público e privado. Ou seja, o paralelismo da representação que separou a CNTE (trabalhadores do setor público) e a Confederação dos Trabalhadores em Estabelecimentos de Ensino CONTEE (trabalhadores do setor privado).

A garantia de tais princípios constitucionais, no entanto, não implica a imediata execução da política educacional por ele vislumbrada, mas desenha um campo cognitivo preciso para a sequência dos conflitos políticos, como alertam Gouveia e Ferraz (2013, p. 118). Dessa forma, pode-se identificar na documentação analisada, que os princípios garantidos na Constituição de 1988 têm se constituído em elementos centrais no âmbito das pautas defendidas pela CNTE, como evidenciam os títulos e os conteúdos das resoluções dos congressos realizados a partir da década de 1990.

O primeiro congresso realizado pela CNTE demarca um tema central para a sua criação, que é a unificação dos trabalhadores em educação, assim denominados os docentes, servidores técnico-administrativos e de apoio às atividades educativas. Tal unificação vai incidir sobre a defesa intransigente, assumida pela Confederação, quanto às condições de trabalho, salário, carreira e formação para toda a categoria, como destaca a resolução do congresso realizado em 1990, ao defender "Plano de Carreira e Piso Salarial Unificado" (CNTE, 1993, p. 7).

Os demais congressos analisados mantêm a defesa dos direitos dos trabalhadores da educação de forma unificada, como a "campanha salarial unificada" (CNTE, 1995, p. 44), luta pela "implementação do Estatuto Único dos Trabalhadores em Educação" (CNTE, 1997, p. 85), defesa da inclusão dos funcionários da escola como profissionais da educação (CNTE, 2005, p. 30; 2008, p. 29), luta pela implementação de uma sólida política nacional de formação de educadores (professores e funcionários de escola), sob a responsabilidade do poder público e com oferta pelas instituições de ensino público superior e luta contra a terceirização e precarização das condições de trabalho, em especial dos funcionários de escola (CNTE, 2008, p. 29-30).

O Piso Salarial Profissional para todos os trabalhadores em educação comparece de forma central em mais de 60\% das resoluções de congresso analisadas (CNTE, 1990, 1991, 1993, 1997, 1999, 2011, 2014 e 2017), já a carreira docente e dos demais trabalhadores em educação é mencionada em $83 \%$ do material consultado, tendo sido consubstanciada no Projeto 
de Lei $n^{\circ}$. 1.592/03, que visa "Estabelecer os princípios e as diretrizes dos planos de carreira para os profissionais da educação básica pública”.

A defesa da educação pública também se constitui em pauta permanente na luta da CNTE, sendo mencionada em 50\% das resoluções, ora relacionada à gratuidade, ora à gratuidade e laicidade e, mais recentemente, integrando outros elementos como inclusão, democracia, tempo integral e qualidade social, como pode-se observar no excerto a seguir:

Mobilizar a sociedade com vistas à ampliação do direito à educação pública, de qualidade social, inclusiva, democrática, laica, de tempo integral, através de mais financiamento público (10\% do PIB para a educação pública), da gestão democrática e da valorização dos educadores (CNTE, 2017).

O financiamento da educação também permeia mais de $50 \%$ das resoluções de congressos analisadas, desde a defesa de verbas públicas exclusivamente para escolas públicas (CNTE, 1995 e 2017) até a garantia de 10\% do PIB para a educação, registrada nas resoluções de congresso de 2002, 2005, 2011, 2014 e 2017.

Mais de 60\% das resoluções pesquisadas registram manifestação da CNTE em defesa da gestão democrática da escola e dos sistemas educacionais, tema do congresso de 1993, continuamente reiterado nos congressos de 1995, 1997, 1999, 2008, 2011, 2014 e 2017, bem como a defesa de seus mecanismos de efetivação, como: "Conselhos escolares soberanos e deliberativos", "Eleições diretas e uninominais para diretor de escola, pela comunidade escolar" e "Liberdade irrestrita para a organização sindical de base nas escolas, grêmios de alunos e organizações dos pais" (CNTE, 1995).

Este panorama inicial evidencia a agenda intensa do debate que compõe-se tanto de temas corporativos quanto do debate educacional na CNTE. Esta articulação do sindicalismo docente entre a defesa da categoria e a defesa da política pública é uma das características identificadas na literatura que define uma certa especificidade ao sindicalismo docente. Diferentes autores destacam a forte presença do conteúdo da política na agenda dos sindicatos de professores (FERREIRA, 2010; FERRAZ e GINDIN, 2014; GINDIN, 2015) e esta primeira aproximação com o conteúdo dos congressos da entidade corrobora esta perspectiva.

\section{Os congressos pós Constituição de 1988: contexto e pautas}

O contex to brasileiro dos primeiros anos de 1990 é marcado pela disputa acirrada entre o projeto de governo decorrente da eleição de 1989, da qual sai vitorioso Fernando Collor de 
Melo (1990-1992), e a perspectiva de estado de proteção social desenhada, ainda que com limites e contradições, na Constituição Federal de 1988. A eleição de Collor representa a inflexão da agenda de proteção social para uma agenda de restrição de direitos. Neste contex to os 3 congressos da CNTE que abrem a década de 1990 - 1990 em Aracajú, 1991 em Olinda e 1993 no Rio de Janeiro - permitem acompanhar a passagem de um contex to propositivo para um contex to de enfrentamento à agenda restritiva do governo Collor.

O Congresso de 1990 é emblemático, pois é o Congresso de Unificação que efetivamente funda a CNTE. Naquele ano observa-se que a defesa da Constituição se dá na direção de regulamentação de direitos e aplicação dos dispositivos previstos em 1988. O Congresso de 1991 tem uma pequena inflexão mais de defesa da manutenção de direitos constitucionais e em 1993, período pós impeachment de Collor, em que já está em curso o governo Itamar Franco (1992-1994). Os elementos extraídos das Resoluções indicam a necessidade de disputar a agenda de reformas na Constituição e de regulamentação dos direitos.

No que se refere ao plano de lutas educacionais observa-se que nos 3 Congressos os temas Piso Nacional e Plano de Carreira são estruturais nas reivindicações. Nos anos de 1990 e 1991 a questão inflacionária é eminente no debate salarial. E em 1993, o tema inflacionário não aparece e ganha força na pauta a dimensão federativa brasileira com a necessidade da pauta organizar a disputa nos estados e municípios.

Quadro 2: Lutas da CNTE a partir das resoluções de congressos 1990, 1991, 1993

\begin{tabular}{|l|l|}
\hline Ano & Destaque com relação especificamente a temas constitucionais \\
\hline 1990 & $\begin{array}{l}\text { Em defesa dos direitos constitucionais: Imediata regulamentação dos direitos sociais } \\
\text { dos trabalhadores definidos pela Constituição de 1988, resguardando e efetivando tais } \\
\text { direitos. Imediata aplicação dos direitos constitucionais aos trabalhadores rurais pela } \\
\text { Constituição de 1988, com regulamentação que resguarde e efetive tais direitos. } \\
\text { Extensão e garantia dos direitos sociais aos trabalhadores aposentados e pensionistas } \\
\text { (p. 6) }\end{array}$ \\
\hline $\begin{array}{l}\text { Defesa da manutenção das conquistas dos trabalhadores na constituição. Estabilidade } \\
\text { no emprego para os servidores públicos. Não redução de salários para os colocados a } \\
\text { disponibilidade. Aposentadoria integral por tempo de serviço. Universidade pública e } \\
\text { gratuita.)(p.19) }\end{array}$ \\
\hline $\begin{array}{l}\text { Pela atuação dos sindicatos, partidos políticos e sociedade organizada: a) nas propostas } \\
\text { de reforma da Constituição sobre formas e sistemas de governo. b)na exigência de } \\
\text { leis que regulamentem os avanços constitucionais assegurados pelo movimento popular } \\
\text { da carta Magna (...) (p.15) }\end{array}$ \\
\hline
\end{tabular}

Fonte: CNTE (1990, 1991, 1993).

Os anos dos governos Collor e Itamar compõem o que Sofia Lerche Vieira (2000) denomina de anos de transição. Tendo a autora como referência pode-se concordar que, apesar 
do início do governo Collor de Mello imprimir uma agenda intensa de reformas que buscavam desconstruir os direitos constitucionais, a efetividade deste processo foi fraca, uma vez que resultou em apenas duas emendas constitucionais em 1992 e nenhuma com força de mudança estrutural.

O enfrentamento a tal agenda pela CNTE pode ser identificado na pauta do Congresso de 1991, que tratou da "defesa dos direitos dos trabalhadores", especialmente destacando estabilidade, aposentadoria integral e não redução de salários. No campo geral das políticas educacionais o governo Collor não deixa marcas profundas e, quando em 1993 a CNTE realiza o XXIV Congresso, o tema do plebiscito sobre a forma de governo no Brasil é central e marca o debate político daquele contexto.

No âmbito das políticas educacionais destaca-se que, no governo Itamar Franco, os embates estavam concentrados em torno do projeto de LDB, em tramitação no Congresso Nacional, e do Plano Decenal de Educação, processo do qual emerge o Pacto pela Valorização do Magistério, que terá um grande protagonismo da CNTE na negociação, portanto fora do embate constitucional. Ainda durante o governo Itamar mais duas emendas constitucionais foram aprovadas, porém com impactos mais diretos nas aposentadorias dos servidores do ensino superior (VIEIRA, 2000).

\section{Os congressos nos anos FHC: reformas e resistência}

O governo Fernando Henrique Cardoso (1995-1998 e 1999-2002) marca uma ruptura emblemática com a perspectiva de proteção social desenhada na Constituição de 1988, dando lugar a uma concepção descentralizadora da ação do Estado (ARRECHT, 2002) com ênfase na mercantilização de serviços e uma perspectiva gerencial de intervenção (FARENZENA, 2006). Durante os dois mandatos exercidos por Cardoso, a Constituição Federal é alterada por 35 emendas constitucionais, muitas delas com efeitos estruturais na agenda educacional do país.

A CNTE realiza 4 congressos neste período - 1995, 1997, 1999 e 2002 - e a agenda sindical cresce em volume de debates. O Congresso de 1995 acontece em Porto Alegre, no primeiro mês do primeiro mandato de FHC, e a avaliação da aliança conservadora que elegeu o novo presidente marca o diagnóstico da conjuntura apresentada no documento do Congresso da CNTE e a agenda de embates que se anunciavam: 
O núcleo econômico da pauta do novo governo FHC é a reforma do Estado (através das privatizações, da lei de concessões e da flexibilização de monopólios), a abertura externa com o aumento de importações de entradas de capitais, a reforma fiscal (renegociação das dívidas e atribuições de Estados e municípios, simplificação tributária, diminuição de gastos e redução dos benefícios previdenciários e a reforma administrativa (com demissão de funcionários e revisão de funções). (CNTE, 1995, p. 11)

Especificamente quanto à Revisão Constitucional, prevista para ser efetivada no Congresso Nacional cinco anos após a promulgação da Carta Magna, a CNTE posicionou-se contrária, e a elegeu como tema no âmbito das lutas gerais da entidade, apresentadas no caderno de teses como não consensual $^{6}$. Porém, o sentido de oposição a uma revisão conservadora da Constituição é apreendido no conjunto das propostas de combate às reformas que diminuíam direitos dos trabalhadores.

Quadro 3: Lutas da CNTE a partir das resoluções de congressos 1995, 1997, 2002.

\begin{tabular}{|c|c|}
\hline Ano & Destaques específicos de temas constitucionais no Plano de Lutas \\
\hline 1995 & $\begin{array}{l}\text { Por uma postura de combate do movimento sindical e popular contra a Revisão } \\
\text { Constitucional. (....) } \\
\text { a) Um dos principais projetos do novo governo FHC é a viabilização da revisão } \\
\text { constitucional, que se constituirá num ataque sem precedentes as nossas conquistas, tais } \\
\text { como: estabilidade no emprego, aposentadoria, isonomia salarial, etc. Propomos uma } \\
\text { campanha em defesa da estabilidade no emprego, da aposentadoria especial e da isonomia } \\
\text { salarial. }\end{array}$ \\
\hline 1997 & $\begin{array}{l}\text { Pelo acompanhamento crítico do Fundo Paulo Renato, visando garantir: gestão de fundos } \\
\text { com a participação dos trabalhadores em educação, através de suas entidades, garantindo } \\
\text { transparência e controle social, ampliação dos recursos para o ensino básico, ampliação da } \\
\text { oferta do ensino fundamental gratuito, piso salarial profissional nacional. }\end{array}$ \\
\hline 1999 & $\begin{array}{l}\text { Contra o "Congresso Revisor" } \\
\text { Pela democratização da vida nacional, aprimorando o sistema proporcional de eleições, } \\
\text { redefinindo o instituto da medida provisória, democratizando os meios de comunicação de } \\
\text { massa, realizando consulta popular acerca dos grandes temas nacionais; (...) } \\
\text { A primeira etapa de implementação do projeto neoliberal na educação foi concluída com a } \\
\text { aprovação da nova legislação - LDB, FUNDEF e parâmetros Curriculares - atendendo às } \\
\text { exigências dos mecanismos (sic) internacionais. A segunda etapa, que compreende o } \\
\text { processo de municipalização e privatização, está em curso. Para impedir a destruição da } \\
\text { educação temos que intensificar nossa mobilização. } \\
\text { Pela revisão da LDB - resgatando o projeto construído pelo Fórum Nacional em Defesa } \\
\text { da Escola Pública. }\end{array}$ \\
\hline 2002 & $\begin{array}{l}\text { Lutar pela revogação da LRF (Lei de Responsabilidade Fiscal) e das Emendas } \\
\text { Constitucionais } \mathrm{n}^{\circ} \text { 14 (que trata da reforma da educação), } 19 \text { e } 20 \text { (referentes à } \\
\text { administração pública e à previdência), considerando os graves problemas gerados nas } \\
\text { relações de trabalho e na vida funcional dos trabalhadores em educação. (...) } \\
\text { Pela aprovação da emenda constitucional no } 112 / 99 \text { (FUNDEB) em substituição ao } \\
\text { FUNDEF. (...) }\end{array}$ \\
\hline
\end{tabular}

${ }^{6}$ Para este ano a pesquisa teve acesso ao caderno de teses do Congresso e não ao documento final do Congresso, assim não se pode dizer neste momento qual foi a tese aprovada em relação a questão da Revisão Constitucional. 


\begin{tabular}{|l|l|}
\hline Exigir dos governos o cumprimento do dispositivo constitucional que assegura o \\
estabelecimento da data base para a revisão anual dos salários. \\
Lutar contra a aprovação das emendas constitucionais $\mathrm{n}^{\circ} 136$ e 137, que tratam da \\
contribuição de aposentados/as e progressividade de alíquotas.
\end{tabular}

Fonte: CNTE (1995, 1997, 1999, 2002)

Os embates educacionais, durante os governos FHC, tiveram na Emenda No. 14 de 1996 um ponto muito forte, assim como em toda a LDB. Os documentos dos Congressos da CNTE não registram a luta em torno da aprovação da referida Emenda, o que pode ser explicado pela periodização dos congressos, entretanto, os efeitos da Lei, com a criação do FUNDEF, são registrados, e a pauta da Revogação da Emenda 14 junto com a Emenda 19 que representou o redesenho da organização do Estado burocrático em direção a uma organização gerencial - estão explicitamente evidenciados na Resolução do Congresso de 2002.

\section{Os congressos nos anos Lula e Dilma: avanços e contradições}

Os governos Lula (2003-2006 e 2007-2010) e Dilma (2011-2014 e 2015-2016), compõem outro período que pode ser analisado em bloco. A chegada no executivo nacional de uma coligação liderada pelo Partido dos Trabalhadores (PT) demarca um período de possibilidades de negociação e permite avanços na agenda da valorização dos trabalhadores da educação (FERRAZ e GINDIN, 2014). Entretanto, tal contexto também é marcado por contradições, dado o conjunto de disputas com grupos privatistas que seguem presentes e ampliam sua organização ao longo do período. A ampliação no âmbito nacional das formas de participação popular na discussão de um projeto educacional, instituído especialmente por meio de conferências (CONEB, CONAES 2010 e 2014) e pela organização do Fórum Nacional de Educação (FNE) marcará o âmbito das disputas educacionais.

Neste período a CNTE realiza 4 Congressos: 2005, 2008, 2011, 2015. O Congresso de 2005 apresenta uma primeira avaliação do governo Lula, destacando a perspectiva de mudança, porém denunciando a morosidade do governo que assumiu com pautas importantes para educação:

No primeiro ano de governo Lula, as políticas implementadas por FHC continuaram, principalmente no campo econômico, a exemplo dos 4,3\% do PIB para educação, a não atualização dos valores do Fundo de Manutenção e Desenvolvimento do Ensino Fundamental e de Valorização do Magistério (FUNDEF) conforme a legislação, a manutenção da Desvinculação das Receitas da União (DRU), assim como, as diretrizes determinadas pelo FMI, 
Banco Mundial, BIRD, OMC com vistas à mercantilização do ensino. (CNTE, 2005, p. 15).

O congresso de 2008 ocorre após a reeleição de Lula como presidente e aponta a pauta do FUNDEB como uma grande vitória da CNTE para o fortalecimento da educação pública. Porém, evidenciam-se tensões, especialmente em relação à questão previdenciária, tema que seguirá forte nos eixos de luta de 2011.

Durante os governos de 2004 a 2016 foram 51 emendas constitucionais, destas, quatro são fundamentais para a estrutura educacional brasileira em termos de regras de financiamento da educação (especialmente a Emenda 53) e, em termos de direito à educação (especialmente a Emenda 59). A síntese das lutas da CNTE neste período revela uma ampliação significativa no número e no detalhamento das reivindicações. O quadro 3 sintetiza alguns destaques desta pauta, que implica questões direta ou indiretamente constitucionalizadas, especificamente da educação, ou articuladas aos temas mais amplos, em especial referentes à previdência.

Cabe destacar novamente que a forma programática da Constituição Federal Brasileira impõe aos governos agendas de reforma constitucional sempre que há inflexão nas perspectivas de ação do Estado. Assim, vários temas da pauta de lutas da CNTE, apesar de não explicitarem diretamente uma análise da Constituição Federal, demandaram debates em torno das reformas constitucionais, caso por exemplo do Piso Salarial Profissional Nacional.

A previsão de um Piso Nacional havia sido suprimida da Constituição pela Emenda 19, no período FHC, e retorna como regra com a Emenda 53 de 2006, a mesma emenda que cria o FUNDEB. Este aspecto reforça a perspectiva de vitória da mobilização da categoria e a manutenção nos planos de luta da necessidade de que a entidade atue mobilizando a categoria para evitar perda de direitos. 
Quadro 4: Lutas da CNTE a partir das resoluções de congressos 2005 a 2014.

\begin{tabular}{|c|c|}
\hline Ano & Destaques específicos de temas constitucionais no Plano de Lutas \\
\hline 2005 & $\begin{array}{l}\text { Atuar no processo de reformas propostas pelo governo, mobilizando a categoria e em } \\
\text { parceria com outros/as trabalhadores/as, a fim de impedir perdas de direitos } \\
\text { conquistados. } \\
\text { Defender a constituição de um Fundo de Manutenação e Desenvolvimento da } \\
\text { Educação Básica e de Valorização do Magistério (FUNDEB), que garanta a } \\
\text { universalização do ensino básico público de qualidade, com financiamento compatível } \\
\text { às necessidades de todas as suas etapas e modalidades. } \\
\text { (...) } \\
\text { Lutar por } 10 \% \text { do PIB para a educação e por ampliação da vinculação federal de } 18 \% \\
\text { para } 20 \% \text { e contra a DRU a fim de garantir recursos para o fundeb }\end{array}$ \\
\hline 2008 & $\begin{array}{l}\text { (...) } \\
\text { Atuar nos processos de reformas propostas pelo governo, mobilizando a categoria e em } \\
\text { parceria com outros/as trabalhadores/as, a fim de impedir perdas de direitos; } \\
\text { Defender a Previdência Pública e lutar contra qualquer reforma que venha retirar } \\
\text { direitos, como o aumento da idade mínima para aposentadoria. } \\
\text { (...) } \\
\text { Mobilizar a sociedade com vistas à ampliação do direito à educação pública, de } \\
\text { qualidade social, inclusiva, democrática, laica, de tempo integral, especialmente através } \\
\text { do financiamento público (aumento do percentual do PIB, conversão da dívida e fim da } \\
\text { DRU) e da valorização dos educadores. } \\
\text { (...) } \\
\text { Articular com os executivos e o parlamento a regulamentação do PSPN, previsto no } \\
\text { artigo 206, VIII, da Consituição Federal, destinado a todos os profissionais da } \\
\text { educação, com base na proposta defendida pelos trabalhadores; } \\
\text { (...) } \\
\text { Lutar pela garantia do modelo de previdência público e solidário e pela aprovação da } \\
\text { PEC 481/O5 (Paralela da Previdência). }\end{array}$ \\
\hline 2011 & $\begin{array}{l}\text { Exigir dos governadores eleitos que retirem o pedido de inconstitucionalida da Lei do } \\
\text { Piso, que está no STF. } \\
\text { (...) } \\
\text { Lutar pela garantia do modelo de previdência público e solidário e pela aprovação da } \\
\text { PEC no 481/O5 (Paralela da Previdência). } \\
\text { Mobilizar a sociedade, com visas à ampliação do direito à educação pública, de } \\
\text { qualidade social, inclusiva, democrática, laica e de tempo integral, especialmente } \\
\text { através do financiamento público (aumento do percentual do PIB) e da valorização dos } \\
\text { educadores. } \\
\text { (...) } \\
\text { Lutar para aumentar o percentual do PIB destinado à educação para 10\%. } \\
\text { Manter a luta pela constitucionalidade e implantação integral da Lei no } 11738 / 08 \text { e } \\
\text { mobilizar a categoria pela regulamentação do Piso Salarial Nacional para todos os } \\
\text { profissionais da educação, previsto no artigo } 206 \text {, VIII, da Constituição Federal de } \\
\text { 1988. } \\
\text { (...) } \\
\text { Lutar pela aprovação do Projeto de Lei no } 1592 / 03 \text {, que visa fixar as diretrizes } \\
\text { nacionais para carreira dos profissionais da educação. } \\
\text { Atuar nos processos de elaboração e debate parlamentar do PNE, a viger entre } 2011 \text { e } \\
\text { 2020, promovendo, também a participação das filiadas. } \\
\text { Priorizar, no PNE, as políticas de financiamento, valorização profissional e gestão } \\
\text { democrática, bem como as estruturas do regime de colaboração, a fim de avançar na } \\
\text { consolidação do Sistema Nacional de Educação. }\end{array}$ \\
\hline 2014 & $\begin{array}{l}\text { (...) } \\
\text { Mobilizar a sociedade com vistas à ampliação do direito à educação pública, de } \\
\text { qualidade social, inclusiva, democrática, laica, de tempo integral, através de mais } \\
\text { financiamento público ( } 10 \% \text { do PIB para a educação pública), da gestão democrática e } \\
\text { da valorização dos educadores. }\end{array}$ \\
\hline
\end{tabular}


Fonte: CNTE (2005, 2008, 2011, 2014)

Observe-se que os temas: Piso, Carreira e Previdência são recorrentes em todo período e indicam uma centralidade na disputa sindical pelos temas de proteção às condições de trabalho do professor. Considerando que a proteção do trabalho no serviço público depende de cada ente federado contraente, as regras gerais contidas de forma programática na Constituição podem ser consideradas como um elemento importante de unidade para a definição da profissão e para a unidade de ação da CNTE na orientação das dezenas de entidades sindicais filiadas. Os embates da Confederação em torno da agenda constitucional é um elemento importante de uma política nacional para a valorização dos trabalhadores da educação.

\section{$5 \quad O$ congresso pós golpe de 2016: novas resistências}

O golpe parlamentar jurídico-midiático, consolidado no ano de 2016, por meio da deposição da Presidente eleita Dilma Vana Rousseff, trouxe consequências imediatas no que se refere à limitação da participação dos movimentos sociais nos processos de elaboração, acompanhamento e avaliação das políticas públicas.

No campo da educação tal limitação se manifesta, entre outros elementos, pelo Decreto Executivo de 26 de Abril de 2017, que revoga a convocatória da III Conferência Nacional de Educação (CONAE 2018), publicada em maio de 2016, transferindo a coordenação da conferência, que seria exercida pelo coordenador do FNE, para a Secretaria-Executiva do Ministério da Educação. Essa alteração confronta o Art. $6^{\circ}$ do PNE (2014-2024) que atribui ao Fórum Nacional de Educação o papel de articular e coordenar as conferências de educação, bem como de acompanhar a execução do PNE e o cumprimento das suas metas (BRASIL, $2014)$.

No sentido de limitar ainda mais a autonomia do FNE, a Portaria ${ }^{\circ} 577$, de 27 de abril de 2017, altera sua composição, reduzindo a participação da sociedade civil. A ingerência na autonomia do FNE se deu pelo desrespeito ao regimento do mesmo, que prevê que é prerrogativa do pleno do Fórum a aprovação da inclusão de alterações na sua composição. $\mathrm{O}$ MEC de forma unilateral publicou uma portaria alterando as entidades que compunham o FNE e, além disso, definiu que para alguns grupos de entidades o próprio Ministério decidiria quem seria titular e suplente. Entre as entidades excluídas na representação estavam Cedes, Forumdir, Contee, Proifes (ANPED, 2017) 
Em resposta as ingerências do MEC em reação ao FNE, 20 entidades realizaram um movimento de renúncia coletiva as suas representações junto ao Fórum, em junho de 2017, criando o Fórum Nacional Popular de Educação (FNPE), considerado um “[ [...] instrumento de resistência em defesa dos avanços e dos espaços de interlocução conquistados" (FORUM NACIONAL POPULAR DE EDUCAÇÃO, 2017, p.O2) e responsável pela organização da Conferência Nacional Popular de Educação (CONAPE). A CONAPE retomou a tradição de conferências organizadas pela sociedade civil, em torno da defesa da Educação Pública e mobilizou etapas municipais, estaduais durante o ano de 2017 e consolidou uma etapa nacional em maio de 2018.

A CNTE realiza em 2017 seu XXXIII Congresso e, novamente abre-se outro bloco de ação, marcado por um conjunto de ações de resistências, evidenciadas no plano de lutas desse congresso. Em relação à participação popular o diagnóstico da entidade é explícito:

A gestão democrática na educação tem sido sistematicamente atacada pelos golpistas do MEC, sobretudo através da tentativa de isolar a atuação do Fórum Nacional de Educação (FNE), importante conquista da sociedade, instituído pela Lei Federal 13.005 (PNE). Embora a $3^{\text {a }}$ Conferência Nacional de Educação (Conae) tenha sido lançada pelo MEC, o governo trabalha no sentido de limitar o financiamento e de inviabilizar a participação de diversos setores, o que requererá esforço extra das entidades que integram o FNE para realizar as conferências preparatórias nos estados e municípios e para viabilizar a presença de todos/as na Conae. Os fóruns e as conferências de educação são importantes espaços de luta e formulação dos educadores, e por isso é preciso lutar por suas manutenções, em caráter democrático, sobretudo através do Comitê Nacional de Luta em Defesa da Educação Pública, que deverá promover ações em defesa desses espaços públicos e de envolvimento da sociedade na defesa de uma educação de qualidade. (CNTE, 2017, s/p).

O governo Temer tem uma intensa atuação legislativa e, em menos de 2 anos aprovou 7 emendas constitucionais, entre estas a Emenda 95, que congelou os gastos primários do governo federal por 20 anos, questão que tem forte impacto em toda a estrutura do financiamento da educação brasileira. O plano de lutas da CNTE explicita mais uma vez elementos importante da disputa legislativa. 
Quadro 5: Lutas da CNTE a partir do Congresso de 2017

\begin{tabular}{|l|l||}
\hline Ano & Destaques específicos de temas constitucionais no Plano de Lutas \\
\hline 2017 & $\begin{array}{l}\text { Mobilizar a sociedade com vistas à ampliação do direito à educação pública, de } \\
\text { qualidade social, inclusiva, democrática, laica, de tempo integral, através de mais } \\
\text { financiamento público (10\% do PIB para a educação pública), da gestão } \\
\text { democrática e da valorização dos educadores; } \\
(\ldots) \text {..) } \\
\text { Garantir a aplicação de verbas públicas para a educação pública - contra a } \\
\text { privatização e a mercantilização da educação; } \\
\text { (...) } \\
\text { Lutar contra a terceirização e a precarização das condições de trabalho, contra as } \\
\text { OSs na educação e contra quaisquer parcerias público-privadas; } \\
\text { (..) } \\
\text { Garantir que os recursos advindos da Lei 12.858/2013, concernentes à União, } \\
\text { sejam imediatamente destinados à ampliação dos recursos do FUNDEB, } \\
\text { compondo a complementação da União adicionalmente aos “10\%” já repassados } \\
\text { pela mesma para este fim; } \\
\text { Retomada da Lei do Piso em sua base original, ou seja, garantir a unidade } \\
\text { nacional sobre o tema da valorização profissional articulando a qualificação da } \\
\text { remuneração inicial com os referenciais mínimos de carreira definidos } \\
\text { nacionalmente por legislação federal; } \\
\text { Garantir uma ampla mobilização nacional para encaminhar a tramitação, no } \\
\text { âmbito do Congresso Nacional, do projeto de lei das Diretrizes Nacionais de } \\
\text { Carreirados trabalhadores em educação; }\end{array}$ \\
\hline \hline
\end{tabular}

Fonte: CNTE (2017)

Este extrato do plano de lutas de 2017 novamente destaca elementos ligados ao financiamento da Educação (percentual do PIB vinculado à educação, combate à privatização e FUNDEB) e condições de proteção ao trabalhador da educação (Piso e carreira), elementos que de forma emblemática são comprometidos com a aprovação da Emenda Constitucional 95.

\section{Considerações finais}

Neste momento da história brasileira, refletir sobre os 30 anos da Constituição Federal é um desafio entre a esperança de que a proclamação de direitos na lei reafirme as possibilidades de disputa e a desesperança de observar o quanto a Carta Magna não tem impedido mudanças bruscas na agenda da política educacional. Ainda que com custos políticos altos de deliberação dentro do Congresso Nacional, a disputa pela constituição tem sido um eixo importante na construção e desconstrução da política pública.

Acompanhar a agenda da CNTE neste período permitiu identificar a trajetória de defesa da educação pública e da proteção corporativa da categoria, articuladas a questões estruturais da organização do Estado brasileiro. Ainda que como uma aproximação a esta 
longa trajetória da maior Confederação de professores no Brasil, foi possível acompanhar a força que a agenda constitucional imprime à agenda sindical.

Este mapeamento abre mais perspectivas de cotejamento do que respostas, pois se os Congressos permitem depreender os momentos mais propositivos e de mais resistência em termos dos períodos demarcados, deixa aberta a necessidade de aprofundar que avaliações e que proposições específicas para cada uma das temáticas foram tecidas entre um Congresso e outro, e que estratégias de intervenção foram desenvolvidas em cada período.

Da mesma maneira, um acompanhamento do conteúdo da agenda traçada pelos Congressos da CNTE registra como o mesmo pode se alterar de um viés extremamente propositivo e construtivo ao simples registro de resistência. Neste ponto, evidencia-se o quanto a participação dos trabalhadores em educação - e poderíamos estender aos diferentes movimentos sociais brasileiros - está condicionada pelo acesso ao interlocutor governamental do momento.

Se uma certa literatura registrou a possibilidade de cooptação dos movimentos sociais quando essa interlocução acontece (ANTUNES, 1997; TUMOLO, 2002), neste artigo, parecenos evidente quão frágil são as instituições democráticas brasileiras. Ou seja, a possibilidade, dos movimentos sociais efetivamente debaterem o conteúdo das políticas públicas, apresentase condicionada não pela qualidade institucional da democracia, mas pela abertura dada por aqueles que ocupam, momentaneamente, o interior do Estado.

Nestes termos, mais que uma descrição das pautas de luta de uma entidade sindical, a análise aqui empreendida oferece o desafio de pensar a democratização da educação e, por que não, a democratização da sociedade brasileira, não apenas pela chave do aperfeiçoamento das instituições - tarefa que nos desafia desde o período da redemocratização após a ditadura militar -, mas também pelo desafio de decifrar e transformar uma cultura política secular, de uma sociedade que ainda se apresenta autoritária e pouco afeita ao debate e ao conflito entre diferentes. Tais características, flagrantes em nossas elites políticas, não lhes são exclusivas, pois as massas que foram às ruas em apoio ao golpe demonstram quanto nosso passado escravocrata pesa como um habitus (BOURDIEU, 2007) nacional de negação do outro.

\section{Referências}

ANPED. MEC dissolve composição do Fórum Nacional de Educação (FNE) e interdita diálogo com a sociedade civil. Portal da ANPED, Rio de Janeiro, ter, 02/05/2017 - 19:01. Disponível em: 
http://www.anped.org.br/news/mec-dissolve-composicao-do-forum-nacional-de-educacaofne-e-interdita-dialogo-com-sociedade. Acesso em 09/06/2018.

ANTUNES, R. Trabalho, reestruturação produtiva e algumas repercussões no sindicalismo brasileiro. In: ANTUNES, R. (Org.). Neoliberalismo, trabalho e sindicatos: reestruturação produtiva no Brasil e na Inglaterra. São Paulo: Boitempo, 1997.

ARRETCHE, M. Relações federativas nas políticas sociais. Educação e Sociedade, Campinas, v. 23, n.80, p. 25-48, 2002.

BOLLMANN, M de G. N.; AGUIAR,L. C. LDB: projetos em disputa. Da tramitação à aprovação em 1996. Revista Retratos da Escola, Brasília, v. 10, n. 19, p. 407-428, jul./dez. 2016. Disponível em: <http//www.esforce.org.br> Acesso em 18 de maio de 2018.

BOURDIEU, P. A gênese dos conceitos de habitus e campo. In: BOURDIEU, P.O poder simbólico. Rio de Janeiro: Bertrand Brasil, 2007.

CNTE Congresso Nacional de Unificação dos Trabalhadores em Educação. Aracajú: CNTE, 1990.

XXIII Congresso Nacional dos Trabalhadores em Educação. Olinda: CNTE, 1991.

XXIV Congresso Nacional dos Trabalhadores em Educação - Gestão democrática: participação popular. Rio de Janeiro: CNTE, 1993.

XXV Congresso Nacional dos Trabalhadores em Educação: educação no centro das atenções: em defesa da escola pública.Porto Alegre: CNTE, 1994.

XXVI Congresso Nacional dos Trabalhadores em Educação: Construindo um Plano Nacional de Educação Democrático e Emancipador. Cuiabá: CNTE, 1997.

XXVII Congresso Nacional dos Trabalhadores em Educação. Terra, Trabalho, Salário e Educação: desafios para o século XXI. Goiânia: CNTE, 1999

XXVIII Congresso Nacional dos Trabalhadores em Educação. Construir outro projeto para o Brasil. Blumenau: CNTE, 2002.

XXIX Congresso Nacional dos Trabalhadores em Educação: Educação pública só é prioridade com mais financiamento: já passou da hora. Brasília, 2005.

XXX Congresso Nacional da CNTE. Educação pública: A diferença que promove a igualdade. Brasília: CNTE, 2008.

XXXI Congresso Nacional da CNTE: a visão dos(as) trabalhadores(as) em educação. Brasília: CNTE, 2011.

XXXII Congresso Nacional da CNTE: educação, desenvolvimento e inclusão social. Brasília: CNTE, 2014.

XXXIII Congresso Nacional da CNTE: Paulo Freire: educação pública, democracia e resistência. Brasília, 2017. 
FARENZENA, N.. A política de financiamento da educação básica: rumos da legislação brasileira. 1. ‥ ed. Porto Alegre, RS: UFRGS, 2006.

FERRAZ, M. Sindicalismo Docente no Brasil: elementos para uma análise. In: GOUVEIA, A. B.; FERRAZ, M. Educação e conflito: luta sindical docente e novos desafios. Curitiba: Appris, 2012.

FERRAZ, M.; GINDIN, J. Sindicalismo docente no governo Lula: desafios de protagonismo e fragmentação. In: OLIVEIRA, R. V.; BRIDI, M. A.; FERRAZ, M. (org.).O sindicalismo na era Lula: paradoxos, perspectivas e olhares.Belo Horizonte: Fino Traço, 2014.

FERREIRA, M. O. V. Sindicalismo docente. In: OLIVEIRA, D. A.; DUARTE, A. M. C.; VIEIRA, L. M. F. DICIONÁRIO: trabalho, profissão e condição docente. Belo Horizonte: UFMG/Faculdade de Educação, 2010. CDROM.

GINDIN, J. Por nós mesmos: o sindicalismo docente de base na Argentina, no Brasil e no México. Rio de Janeiro: Azougue, 2015.

GOHN, M. G. M. Lutas e movimentos pela educação no Brasil a partir de 1970. EccoS-Rev. Cient., São Paulo, v. 11, n. 1, p. 23-38, jan./jun. 2009. Disponível em: $<$ https://www4.uninove.br/ojs/index.php/eccos/article/view/1535/1306>. Acesso em 18 de maio de 2018.

GOUVEIA, A. B.; FERRAZ, M. Sindicalismo Docente e Política Educacional: tensões e composições de interesses corporativos e qualidade da educação. Educar em Revista, v. 48, p. 111-129, 2013.

JINKINGS, I. O golpe que tem vergonha de ser chamado de golpe. In: JINKINGS, I.;

DORIA, K.; CLETO, M. (Orgs.). Por que gritamos o golpe? Para entender o impeachment e a crise política no Brasil. São Paulo, SP: Boitempo, 2016.

PAOLI, M. C.; TELLES, V. S. Direitos sociais: conflitos e negociações no Brasil Contemporâneo. In: ALVAREZ, S. E.; DAGNINO, E.; ESCOBAR, A. Cultura e política nos movimentos sociais latino-americanos: novas leituras. Belo Horizonte: UFMG, 2000.

TUMOLO, P. S. Da contestação à conformação: a formação sindical da CUT e a reestruturação capitalista. Campinas: Unicamp, 2002.

VIEIRA, S. L. Política Educacional em Tempos de Transição: 1985-1995. Brasília: Plano, 2000. 